\title{
Dialectics of resilience: a multi-level analysis of a telehealth innovation
}

\author{
Sunyoung Cho ${ }^{1}$, Lars Mathiassen ${ }^{1}$, Daniel Robey ${ }^{2}$ \\ ${ }^{1}$ Center for Process Innovation, Georgia State University, Atlanta, GA, USA; \\ ${ }^{2}$ Department of Computer Information Systems, Georgia State University, Atlanta, GA, USA
}

\section{Correspondence:}

S Cho, Center for Process Innovation, Georgia State University, 35 Broad St NW Suite 400, Atlanta, GA 30303, USA.

Tel: + 1404463 9290;

Fax: +1 404463 9292;

E-mail: sunyoung.cho@ceprin.gsu.edu

\section{Abstract}

Resilience is commonly portrayed as a positive capability that allows individuals, groups, and organizations to thrive in dynamic contexts. This paper questions this oversimplified view based on a dialectical analysis of a telehealth innovation within a network of collaborating hospitals. We analyze the major contradictions that characterize the adoption of the innovation. First, we analyze contradictions between individuals and groups within each adopting organization. Second, we analyze contradictions between the adopting organizations. This multi-level analysis leads to a deeper understanding of resilience as a dialectical process. The analysis of the case shows that, although the participating individuals, groups, and organizations demonstrated apparent resilience in adopting the telehealth innovation, the innovation remained in a fragile state, where it was unclear whether it would continue to diffuse, stabilize as-is, or slowly deteriorate. Hence, while resilience facilitated swift and successful adoption, it also created tensions that endangered further diffusion and the long-term sustainability of the telehealth innovation. We suggest that understanding the future success of the innovation would be facilitated to a large extent by a dialectical analysis of the involved contradictions.

Journal of Information Technology (2007) 22, 24-35. doi:10.1057/palgrave.jit.2000088

Published online 19 December 2006

Keywords: resilience; dialectics; telehealth innovation

\section{Introduction}

\section{$\mathbf{T}$} he use of information technology (IT) within healthcare is increasing because of the information-intensive nature of the industry (Anderson, 1997; Dwivedi et al., 2001). The investments in IT within healthcare have grown rapidly and were expected to reach 23.6 billion USD in 2003 , rising at a rate of $9.3 \%$ from $\$ 21.6$ billion expended in 2002 (News release of Sheldon I. Dorenfest \& Associates, Ltd. http://www.dorenfest.com/pressrelease_feb2004.pdf). This growth is not surprising and will likely accelerate given that IT infrastructure and services in healthcare are estimated to be 10-15 years behind other industries, such as banking, airlines, and manufacturing (Raghupathi, 1997). Since the late 1990s, telehealth innovations that include provision of healthcare services, clinical information, and education over distance using telecommunication technology have attracted special attention (Maheu et al., 2001).

The growing investment in IT within healthcare has led to increasing research interests and experiments with healthcare and telehealth innovations (Chiasson and
Davidson, 2004). Many of these studies investigate the particular problems that are related to implementation of IT-based innovations within the healthcare industry (Tanriverdi and Iacono, 1998; Aarts and Peel, 1999; Berg, 2001; Lorenzi and Riley, 2003). Different types of explanations for implementation problems are provided, including knowledge barriers and management issues (e.g. Tanriverdi and Iacono, 1998; Dwivedi et al. 2001), people and organizational issues (e.g. Lorenzi et al., 1997; Aarts et al. 1998; Berg, 2001), social communication patterns (Davidson, 2000), organizational structure and culture (Bangert and Doktor, 2003), and enactments of different structures of reference by different stakeholder groups (Constantinides and Barrett, 2006). These studies point to the importance of organizational processes in explaining the success and failure of telehealth innovations.

The purpose of this study is to continue this line of research by investigating the relationship between organizational resilience and adoption of telehealth innovations. 
According to the literature, resilience refers to the capability of individuals, groups, or organizations to adapt quickly to changes in their environments (Horne III 1997; Mallak, 1998; Coutu, 2002; Hamel and Valikangas, 2003; Riolli and Savicki, 2003; Starr et al., 2003). We base our analysis on an in-depth case study of a telehealth innovation adopted in a network of collaborating hospitals. The adopting organizations and the key groups, and individuals involved arguably demonstrated considerable resilience, resulting in successful implementation. However, many indicators suggest that the innovation reached a temporary and in some respects fragile acceptance, from which it might be unable to progress. To understand this outcome, we conduct a dialectical analysis (Israel, 1979; Bjerknes, 1991; Mathiassen, 1998; Robey and Boudreau, 1999; Robey et al., 2002) of the major contradictions that characterize this particular adoption initiative. We analyze contradictions at two levels of analysis: within each adopting organization and between the adopting organizations. This analysis is guided by the following research questions:

1. How is resilience manifest at the organizational and inter-organizational levels of analysis in the adoption of a telehealth innovation?

2. How can the use of dialectics augment the analysis of resilience in the adoption of a telehealth innovation?

We argue that the future of the innovation depends upon the development and resolution of the involved contradictions. This analysis leads us to an understanding of the dialectics of resilience in relation to adoption of IT-based innovations in organizational contexts.

The study makes three distinct contributions. First, it contributes to research on organizational resilience (Weick, 1993; Horne III 1997; Mallak, 1998; Coutu, 2002; Hamel and Valikangas, 2003; Riolli and Savicki, 2003) by exploring the concept in relation to organizational adoption of IT-based innovations. We suggest that resilience in relation to adoption of innovations is an elusive concept inviting interpretations from multiple and often contradictory perspectives. Specifically, we argue that contemporary definitions of resilience raise interesting issues related to the dynamics of adoption behaviors and to interactions between different levels of analysis. Second, the study adds to our knowledge of dialectics, which is already established as a useful approach to IS research (Bjerknes, 1991; Mathiassen, 1998; Robey and Boudreau, 1999; Robey and Holmstrom, 2001; Robey et al., 2002; Sabherwal and Newman, 2003) and to organization studies in general (Ford and Ford, 1994; Das and Teng, 2000; Rond and Bouchikhi, 2004). Building on this tradition, we demonstrate a detailed approach to conceptualizing, identifying, and analyzing contradictions to uncover the complex dynamics involved in adoption of IT-based innovations. Finally, the study adds to our understanding of the challenges involved in adopting and managing telehealth innovations in an inter-organizational context.

The argument is structured as follows. The next section presents the theoretical foundation for the study by reviewing the literature on organizational resilience and on the use of dialectics in organization studies. After a discussion of the adopted research approach, we continue with a dialectical analysis of resilience in relation to adoption of the telehealth innovation under examination. Finally, we discuss the contribution of this research and its implications for both research and practice.

\section{Theoretical foundation}

In this section, we review the two lines of research that this study builds on and contributes to: the literature on organizational resilience and the literature on the use of dialectics in organization studies.

\section{Resilience}

Resilience research has its origin in psychology (Coutu, 2002). It started with pioneering studies by Norman Garmezy of different responses and attitudes of children, whose parents were schizophrenic. Garmezy concluded that a quality of resilience played a role in the mental health of those children. Since then, many studies have been carried out and theories abound about characteristics of resilience (Coutu, 2002). The majority of these studies are at the individual level. Horne III and Orr (1998) note that the term resilience began to be applied as an organizational quality in the early 1990s. More recently, the concept of the 'resilient organization' has gained popularity as a quality that might help organizations, and groups within organizations survive and thrive in difficult or volatile environments (Riolli and Savicki, 2003).

Most definitions of resilience as an organizational quality emphasize its relationship with effective adaptation. Mallak (1998) defines resilience as the ability of an individual, group, or organization to expeditiously design and implement positive adaptive behaviors matched to the immediate situation, while enduring minimal stress. Mallak considers organizational resilience as closely related to individual employees' resilience. Hamel and Valikangas (2003) define resilience as the ability to dynamically reinvent business models and strategies as circumstances change. Starr et al. (2003) use the term 'enterprise resilience' as the ability to withstand systemic discontinuities and adapt to new risk environments. Horne III (1997) defines resilience as 'a fundamental quality of individuals, groups, organizations, and systems as a whole to respond productively to significant change that disrupts the expected pattern of events without engaging in an extended period of regressive behavior' (p. 31). In general, these definitions carry positive connotations. The underlying assumption is that resilient organizations thrive in dynamic environments.

For the sake of theoretical clarity, it would be better if the concept of resilience were decoupled from the concept of effective adaptation. Organizational resilience should be conceptually distinct from the outcomes with which it is associated. If it is not conceptually distinct, resilience becomes conflated and confounded with effective adaptation and its explanatory powers are removed. Reinmoeller and Baardwijk (2005) offer from that point of view a more promising approach in which resilience is regarded as a process capability, instrumental in overcoming barriers to change and in developing multiple sources of competitive advantage. Three advantages to this approach seem apparent. First, resilience is related to the process of 
change, where specific capabilities may play roles in overcoming specific barriers to change. Second, resilience is multi-faceted, not a single quality. Thus, organizations may possess some resilient capabilities and not others. Third, in a process perspective, resilience becomes a capability that may be related to both successful and unsuccessful adoption behaviors. For example, under conditions of external threat, an organization might quickly adopt an innovation without any certainty that it will be sustained in the long run. Indeed, resilient responses in the short run might neglect more fundamental, organizational capabilities related to long-run performance.

The process perspective on resilience is consistent with the usage of the term in ordinary language. The Advanced Learner's Dictionary of Current English defines resilience as the 'quality or property of quickly recovering the original shape or condition after being pulled, pressed, crushed etc.' (Hornby, 1998). In the context of adoption of IT-based innovations, this definition allows for two different and quite opposite interpretations. On the one hand, this definition can imply that a resilient organization is able to adopt an innovation and quickly recover from the interruption, and return to serving its mission. On the other hand, this definition can also imply that a resilient organization is able to absorb or reject an innovation without any significant change. The ordinary language definition is neutral, allowing quite opposite interpretations of how organizations manage innovation adoption challenges. In either case, however, the question remains: is it in the long-term interest of an organization to resiliently adopt (or abandon) the innovation in question?

When applied to organizational adoption of IT-based innovations, the concept of resilience remains elusive and raises two specific issues of interpretation. First, there are interesting issues related to the dynamics of adoption of innovations, as when organizations successfully implement innovations, and later return to traditional practices because the innovations were not sufficiently institutionalized. In such cases, there is potential benefit to interpreting resilience over time from a process point of view. Second, there are interesting issues related to human agency in adoption practices. Resilience is not an abstract organizational capability. It needs to be interpreted as specific and complex interactions between different levels of adoption behavior including individuals, groups, and organizational units. In other words, the analysis of resilience requires researchers to address levels-of-analysis issues (Klein and Myers, 1999). Resilience can be a single-level or a multilevel construct depending on the research context. As many IT-based innovations are networked and distributed, their adoption is enacted through complex social networks of multiple stakeholders. There is, therefore, a need to address issues related to level of analysis when applying resilience as a theoretical lens in this particular domain.

In summary, resilience is employed in this paper as a framework for studying adoption of IT-based innovations. We tentatively accept Reinmoeller and Baardwijk's definition of resilience as process capabilities existing at multiple levels of analysis including individuals, groups, and organizations. However, we augment this definition with a consideration of dialectics and contradictions to support a process view that decouples resilient adoption behaviors from adoption outcomes and allows us to engage in opposing interpretations of how organizations manage innovation adoption challenges.

\section{Dialectics}

Organizational change has been the subject of extensive research in the fields of both management (Ford and Ford, 1994; Van de Ven and Poole, 1995) and information systems, due to IT's role in organizational change (Robey and Sahay, 1996; Mathiassen, 1998). Dialectics has been adopted as one approach to understand and study social phenomena in general, and it has proven particularly useful as a framework to understand issues related to social change. Dialectics has been adopted in many organizational studies (Ford and Ford, 1994; Das and Teng, 2000; Rond and Bouchikhi, 2004; Chae and Bloodgood, 2006) as well as in many information systems studies (Bjerknes, 1991; Mathiassen, 1998; Robey and Boudreau, 1999; Robey and Holmstrom, 2001; Robey et al., 2002; Sabherwal and Newman, 2003; Chae and Bloodgood, 2006).

The core concept in dialectics is contradiction, for which a variety of definitions have been applied. According to Van de Ven and Poole (1995), dialectics assumes that organizations exist in a pluralistic world of colliding events, forces, or contradictory values that compete with each other for domination and control. The organizational consequences of IT can, therefore, be explained by reference to the relative strength of opposing forces, some promoting change and others opposing change (Robey and Boudreau, 1999). Other researchers build on Mao Tse Tung's more elaborate notion of contradiction to analyze social processes (Bjerknes, 1991; Israel, 1979; Mathiassen, 1998). Contradictions in these studies are seen as totalities that consist of two opposing elements. The opposites of a contradiction have two qualities - the identity of, and the struggle between the opposing elements. The identity refers to the contradiction as a whole and explains the paradox in which the opposing elements co-exist. The struggle emphasizes the dynamics that drive change. In any given situation, the relationship between the two opposites is usually uneven so that one of the opposites exerts more influence. As time passes, the relationship between the opposing elements might change as a result of their mutual struggle. Also, there are typically several contradictions in any given situation, each with elements becoming more or less dominant as the situation evolves.

We see the different notions of contradictions discussed above as complementary. The main commonality underlying these understandings is their perspective that change is the outcome of contradictory forces. Put differently, the struggle between contradictions and between the opposites of each contradiction are the main forces driving change. In this study, we adopt dialectics to analyze a situation where a telehealth innovation has been adopted by multiple organizations. Following Rond and Bouchikhi (2004), our assumption is that dialectics will help reveal the contradictions involved and that this, in turn, can lead to an understanding of key forces involved in shaping the present situation and the future trajectory of the telehealth innovation.

To support a detailed analysis of relevant contradictions, we follow Bjerknes' (1991) suggestion for identifying and 
analyzing contradictions. This analytic process occurs in three steps: (1) define specific contradictions; (2) analyze each contradiction's identity and struggles involving the two opposing elements; and (3) synthesize by considering all contradictions involved in the situation. To identify contradictions in the situation under investigation, we combine two sources. First, Bjerknes (1991) proposes focusing on conflicts, or antagonistic contradictions, while putting less emphasis on contradictions in which potential conflicts are temporarily resolved. Second, Robey and Boudreau (1999) and Robey et al. (2002) suggest that opposing forces may align with specific interest groups, or they can be conceived more abstractly, for example, as cultural assumptions, institutionalized values, or organizational memory. However conceived, contradictions can be identified and analyzed between different levels of social analysis (Bacharach et al. 1996).

\section{Research method}

\section{Research context}

In March 2003, the department of neurology at a large university hospital (referred to as the hub hospital) in the state of Georgia in the US launched a telehealth innovation named REACH (the Remote Evaluation for Acute Ischemic Stroke Program). This 'telestroke' system allowed neurologists from the hub hospital to use telecommunication to participate in real-time stroke assessments for patients in rural hospitals. The innovation was first implemented in one rural hospital and gradually expanded to a number of hospitals, with initial technical problems being detected and resolved effectively. At the time of our study between December 2004 and February 2005, the innovation had been adopted by seven rural hospitals. Between March 2003 and May 2004, doctors had used REACH to evaluate 75 patients and to qualify 12 of them for treatment.

The need for the REACH system was justified by the critical lack of stroke specialist expertise in most rural areas and in many urban areas as well. This contributes to a higher rate of stroke deaths in rural and underserved communities (Casper et al., 2003). For the case of nonbleeding, or ischemic stroke, a blood-clot dissolving agent called tPA (tissue plasminogen activator) greatly reduces chances of severe disabilities if it is administered within 3 hours from the first show of stroke symptoms. However, it is estimated that only $2 \%$ of stroke patients receive its benefits, partly due to a lack of on-site stroke specialists. It is essential that a stroke specialist examine each stroke patient before tPA is applied. It is far from trivial to distinguish non-bleeding from bleeding cases, and applying tPA to a bleeding case will have immediate and most likely lethal consequences. Providing the services of stroke specialists over distances can therefore significantly increase the rate of tPA use, save many lives, and reduce chances of permanent disabilities.

The REACH system makes the hub hospital's stroke specialists available to examine patients at distant rural hospitals round the clock. It enables these neurologists to hear and see the patients in real time. A patient admitted to one of the participating rural hospitals gets a computerized tomography (CT) scan to help pinpoint the cause and location of the stroke, while the hub hospital is notified about the incident and the on-call neurologist is connected. The patient is then moved to a room where the telestroke cart is located, and an emergency room (ER) nurse enters the patient's information and lab results into the system. The hub hospital neurologist, now connected to the rural hospital through $\mathrm{REACH}$, evaluates the patient on a standardized stroke scale through video-based interactions while seeing CT scan results and lab data on a screen. Voice communication between the neurologist and the clinicians and patient at the rural hospital is conducted over a landline telephone. Decisions on tPA administration and possible patient transfer are then made by the neurologist.

The implementation and operation of the REACH system were financed by the hub hospital, except that each rural hospital was responsible for the CT scanner and system infrastructure, including the fast network connection. The cost of building the telestroke cart with all necessary telecommunication, data processing, and video equipment for each rural hospital was paid by the hub hospital, and technical trouble-shooting was covered by the hub hospital's dedicated systems developer.

\section{Case study design}

A case study approach was adopted to study this telehealth innovation in the social context of the hub and rural hospitals. This choice is consistent with Yin's suggestion to consider three conditions to choose a proper research method: (1) the type of research questions posed; (2) the extent of control an investigator has over actual behavioral events; and (3) the degree of focus on contemporary as opposed to historical events (Yin, 2003). First, a case study has advantages over other research methods, such as surveys and experiments in answering questions of 'how' and 'why.' Our research questions deal with explaining how a telehealth innovation is influenced by organizational processes traced over time. Second, our control over certain variables is not of concern in this study and we have no intention or ability to manipulate the involved behaviors. Finally, we are interested in a contemporary phenomenon of a telehealth innovation within a real-life context as opposed to historical events. In addition, there is broad consensus among researchers that a case study approach is particularly well suited to study the development, implementation, and use of IT-based innovations in organizational contexts (Benbasat et al., 1987; Darke et al., 1998).

The research was designed as a single case study with multiple sites involved. Thus, we define the case as the network of adopting hospitals. This definition allows us to examine relationships at different levels of analysis within the network and within individual hospitals. Despite some limitations, single cases allow researchers to investigate phenomena in depth to provide a rich understanding of them (Walsham, 1995). Data sources included complete analysis of the telestroke encounter process, systems documentation, demonstration of $\mathrm{REACH}$, site visits to the hub hospital and four rural hospitals, stakeholder interviews, and other sources (see below).

Two of the authors participated in the field interviews. We interviewed 27 individuals in five hospitals including the hub and four rural hospitals. Seven were doctors, five 
Table 1 Interviewee profiles

\begin{tabular}{lcl}
\hline Interviewee position & Number of interviewees & Organization \\
\hline Doctor & 7 & $\begin{array}{l}\text { Four neurologists at the hub hospital } \\
\text { Three neurologists at the rural hospitals } \\
\text { Rural hospitals }\end{array}$ \\
$\begin{array}{l}\text { Nurse } \\
\text { Administrative staff }\end{array}$ & 9 & $\begin{array}{l}\text { One vice president at the hub hospital } \\
\text { Two CEOs at two of the rural hospitals }\end{array}$ \\
& 5 & $\begin{array}{l}\text { One CFO at another rural hospital } \\
\text { Two at the hub hospital } \\
\text { One at a rural hospital } \\
\text { Rural hospital } \\
\text { A start-up independent of the hub hospital }\end{array}$ \\
IT staff & 3 & 1
\end{tabular}

administrative staff, three technical staff, nine nurses, one radiology technician, and two entrepreneurs. Table 1 summarizes the profiles of the interviewees. All interviews were semi-structured, lasted typically $30-60 \mathrm{~min}$, and were recorded on audio tape. Most of the interviews were individual except for four group interviews with either two or four participants. We generated field notes immediately after each interview to summarize the key content and to suggest possible interpretations. Later, all the interviews were transcribed.

To support and verify interviews, other sources were sought and analyzed as well. For example, to verify local reimbursement practices, we obtained the patient demographic information for the participating rural hospitals. The project-related documents and scientific grant proposals for REACH were also analyzed. In addition, local newspaper articles and the hub hospital newsletters were analyzed, providing supplementary information about the rollout of REACH.

Based on the interview notes and all related documents, the two field researchers developed content coding categories related to resilience in the adoption of the telehealth innovation. As a result, a comprehensive list of existing and potential contradictions for organizational resilience in the telehealth adoption was developed. This process was guided by the suggestions of Bjerknes (1991), Robey and Boudreau (1999), and Robey et al. (2002) with focus on contradictions among different stakeholder groups. The analysis revealed an initial set of 10 intraorganizational and five inter-organizational contradictions. These two sets of contradictions related to adoption of the telehealth innovation were then grouped into more abstract categories of contradictions through rounds of discussions among all three authors. Disagreements among the authors were resolved with arguments based on evidence from the collected data. Through several iterations, a final set of three intra-organizational and three inter-organizational contradictions of relevance to the study was produced. These contradictions are summarized in Table 2, which also presents the results of our analysis.

\section{Results}

In this section, we provide a multi-level analysis of the adoption of REACH. First, we consider the resilience of the project initiator group; we then analyze the identified intraorganizational contradictions within each of the adopting organizations; finally, we analyze the identified interorganizational contradictions within the network of adopting organizations, including a new organization that emerged to commercialize the innovation.

\section{Resilient adoption}

REACH was conceived by two neurologists working at the hub hospital. They were aware that the blood-clot dissolving drug, tPA, was extremely underused in rural areas because of lack of stroke specialists. Their medical vision was to demonstrate the possibility of applying tPA through the use of telehealth innovations. In 2001, they launched a systems development effort sponsored by the neurology department and the hub hospital. A core team was formed consisting of four stroke specialists and a dedicated systems developer to lead and conduct the innovation effort. All team members were patent owners of REACH, and they championed the innovation by visiting, persuading, and training clinicians and medical staff in the rural hospitals. The core team was also able to garner support for the project from CEOs of some rural hospitals within a $2-h$ driving distance from the hub hospital.

The individuals in the core team were very enthusiastic about REACH, its features, and its considerable potential for providing the neurological expertise required to apply tPA treatment in remote stroke incidents. They all shared the clinical and scientific vision that REACH could save stroke patients' lives and save many from permanent brain damage. They also realized the potential of telehealth services in other clinical practices and took pride in being pioneers in providing neurological services remotely. The members of the core team reacted swiftly to new technological opportunities in their environment; they formed a vision for telehealth innovation that could effectively extend available treatment opportunities (tPA) beyond current medical practices; and they created funding and formed a project that successfully realized that vision in collaboration between the hub and rural hospitals. In this way, the core group and the involved individuals demonstrated resilient adoption behavior.

The hub hospital also demonstrated resilience by proactively adopting telehealth innovations. The vice 
Table 2 Contradictions in adopting REACH

\begin{tabular}{|c|c|c|c|}
\hline Level & Contradiction & Identity & Struggle \\
\hline $\begin{array}{l}\text { Intra- } \\
\text { organizational }\end{array}$ & $\begin{array}{l}\text { Medical vs business } \\
\text { interests }\end{array}$ & $\begin{array}{l}\text { The long-term survival of } \\
\text { any healthcare organization } \\
\text { depends on two opposites: } \\
\text { provision of quality medical } \\
\text { services and a sustainable } \\
\text { business model }\end{array}$ & $\begin{array}{l}\text { The medical interests of the } \\
\text { initiators of the innovation } \\
\text { were not aligned with the } \\
\text { business interests of the hub } \\
\text { hospital }\end{array}$ \\
\hline
\end{tabular}

Consequence

Had more influence in development and early adoption stages

Emerging $v s$ institutionalized work practices

\section{IT innovations are contextualized against existing work practices, transforming them to some degree}

The emerging work practices around the telehealth innovation departed from the existing, institutionalized work practices

IT-based innovation $v s$ established IT infrastructures

Inter- Economic organizational incentives of hub hospital $v s$ rural hospitals

Emerging medical practices $v s$ institutionalized insurance practices

IT innovations build on and require changes in an organization's IT infrastructure

Urban hospitals and rural hospitals constitute different, but mutually dependent parts of the U.S. healthcare system

Institutionalized insurance practices provide primary support for medical services, but they also define the conditions under which such services must be provided
Hub hospital interests $v s$ commercial explorations

\section{Any commercialization} effort must be aligned with the interests of the initiating hub hospital
The telehealth innovation was not designed with the existing IT infrastructure and capabilities of the adopting organizations in mind

The telehealth innovation implied different economic incentives for the hub hospital and the rural hospitals

The emerging medical telehealth innovation were not aligned with current insurance regulations for reimbursement

\section{Conflicts of interests}

between the hub hospital and commercialization explorations derailed the negotiation process practices resulting from the
Could be observed but had not yet emerged as significant

Had been recognized during the adoption at each rural hospital and will continue to impact further adoption initiatives

Had been recognized but not addressed

Had been recognized from early on but was emerging as an issue

The first commercialization initiative failed president of the hub hospital noted that 'creation of a virtual delivery system is an ultimate goal and it is a winwin strategy in competition.' According to him, the hub hospital had not sufficiently exploited its highly qualified medical staff because it served a rather small population base in competition with several other large hospitals. Forming alliances with rural hospitals and clinics seemed like a viable business model and growth strategy for the hub hospital. This would allow the hub hospital to provide clinical services to rural hospitals through systems like REACH and thereby, effectively increase the number of patient referrals. Hence, the hub hospital recognized opportunities and threats in the environment, searched for new business models, and financially supported innovations like $\mathrm{REACH}$, evidencing its resilience.

The network of participating rural hospitals also saw new opportunities related to this particular telehealth innovation.
They were in many ways enthusiastic about REACH. According to one CFO at a rural hospital, about two-thirds of the rural hospitals were operating in the red and two of the four rural hospitals involved in REACH reported operational deficits in the previous fiscal year. It was common for regional hospitals to have severe shortages of specialists like neurologists, psychiatrists, and pediatricians. One nurse said that many rural hospitals were considered by local patrons as a 'band-aid station,' providing only temporary treatment. The rural hospitals saw opportunities to compensate for shortages of stroke specialists through REACH and to provide better clinical service and build their reputations through such telehealth innovations, even though they had no explicit revenue model for using the REACH system. In this sense, the rural hospitals demonstrated resilience by improving their practices and expanding their client base through adoption of the telehealth innovation. 
Given these findings and the track record of 75 evaluated patients and 12 tPA treatments, it is fair to say that the individuals, groups, and organizations involved demonstrated the resilience required to successfully develop and adopt REACH, a radically new type of IT-based innovation that differed from previous practices at both the hub and the rural hospitals. But how sustainable was the innovation? Despite the project initiators' enthusiasm and support, the system subsequently faced problems of financing continued expansion. The volume of usage remained low, generating problematic cost-benefit comparisons. Moreover, issues related to turning $\mathrm{REACH}$ into a fully institutionalized medical practice remained unresolved. To understand these issues more completely, we explore the demonstrated resilience from a process perspective by analyzing the contradictions involved in REACH. The major contradictions identified in REACH on both the intra- and interorganizational levels are summarized in Table 2.

\section{Intra-organizational contradictions}

We identified three major contradictions related to REACH within the hub hospital and the adopting rural hospitals.

\section{Medical vs business interests}

Provision of high-quality and state-of-the-art medical services is central to any healthcare organization. At the same time, however, the organization should have a sustainable business model to maintain its long-term existence. In that sense, the medical interests and the business interests are mutually dependent. This intrinsic relationship between two opposites constitutes the identity of this contradiction. In this case, we found these opposing elements to be in struggle. The medical interests had driven the development of the innovation without being aligned with the business interests of the hub hospital. REACH was first conceived as an academic pilot project, and the initiators did not explicitly consider the system's underlying business model. The following remark by one of the hub hospital neurologists illustrates the lack of consideration for business interests among the project initiators and champions:

I don't have any business savvy. I know the system has been pushed through. I think it's been in the pipeline now for a year and a half or two years to get a patent on it. I don't know what to do with the patent after we have it.

The medical interests dominated the business interests in the early development and adoption phases. Subsequently, when the system was actually being used at multiple sites, the struggle between the two opposites emerged as a conflict. One problem was that medical services provided from the hub hospital through the system were not properly reimbursed. In fact, the services that the central neurologists provided over the system were not properly reimbursed. Also, the hub hospital only had vague estimates of the system's impact on referrals, and the rural hospitals expressed concerns about the low reimbursement for stroke patients from Medicare and Medicaid.

\section{Emerging vs institutionalized work practices}

Adoption of IT innovations does not occur in a vacuum. Innovations are introduced into the context of existing work practices, transforming them to some degree. The newly emerging and the existing work practices constitute in this way, two opposites that eventually need to be reconciled in new, institutionalized work practices for the adoption to be successful. This intrinsic relationship between old and new work practices constitutes the identity of this contradiction. The struggle between the opposites was in this case expressed as differences between emerging and existing work practices at the rural hospitals. REACH required extensive inter-departmental and inter-organizational communication and coordination, a practice that was quite different from existing work practices in the involved rural ERs. One interviewee at a rural hospital said that, before REACH, they had not experienced such intensive communication and coordination between the emergency medical service unit, the radiology department, and the ER staff. Training and education of staff was an essential mechanism to overcome the gap between old and new practices. Initial training of rural hospital staff was provided by the hub hospital, and many of the rural hospitals later conducted their own training as needed. However, the struggle was not effectively resolved. In one rural hospital, the volume of system usage was extremely low with only three cases over an 18-month period of system operation. One nurse expressed concerns about using REACH, following so few actual encounters with the system:

Yeah, we probably do need to set up an annual training program. (It) would be good just so everybody - this is how you do it, you know... . Anything that you don't use often, you know, can bring that feeling on like, oh, am I going to do it right.

Overall, the struggle of the opposites had yet to become manifest as a serious conflict because of the recent adoption of REACH and the small number of adopting hospitals. The institutionalized work practices were, however, only changing slowly, due in part to limited use and to limited opportunities to learn new practices.

\section{IT-based innovation vs established IT infrastructures}

Like any other IT-based innovation, REACH built on and required changes in the rural hospitals' IT infrastructure. The mutual dependency between the telehealth innovation and the capabilities of the available IT infrastructures within each rural hospital constitutes the identity of this contradiction. The two opposites were in struggle as REACH was not designed with the existing IT infrastructure of the rural hospitals in mind. REACH required certain IT capabilities and infrastructures in place for its operation, for example, high-speed internet connections and digital CT scanners. However, some of the adopting rural hospitals lacked these capabilities. Also, most of the rural hospitals did not have fulltime IT employees. Those that did experienced high turnover of IT staff, making it difficult for the rural hospitals to maintain the needed IT capabilities. This struggle between the telehealth innovation 
and the IT infrastructure of the adopting hospitals was recognized from the early adoption stages. This struggle was expressed by the technology manager, who was hired by the hub hospital and provided the technical support for the participating rural hospitals through frequent visits:

You must have a high speed bandwidth, at least 512 or 768. You must have the appropriate network drops in the CT scan room and in the emergency room. You must have the appropriate interfaces so that you can interface the CT scanner to the interface, and they were not able to or have been hesitant about providing those things.

\section{Inter-organizational contradictions}

We identified three major contradictions related to REACH involving the adopting hospitals, the hub hospital, and other related organizations.

\section{Economic incentives of hub hospital vs rural hospitals}

Urban hospitals and rural hospitals constitute different parts of the US healthcare system. Rural hospitals serve smaller population bases and are geographically scattered around the nation, whereas urban hospitals serve larger populations with more resources and a more diverse portfolio of medical expertise. Urban hospitals support rural hospitals as well. Urban and rural hospitals are mutually dependent in that they cannot efficiently serve the entire population without each other. This interdependence between the economic incentives of the hub hospital and the rural hospitals to adopt telehealth innovations constitutes the identity of this contradiction. The introduction of REACH engaged the opposing incentives in a struggle, as the innovation generated increased revenue for the hub hospital through stroke patient referrals. This is illustrated by the following informal economic estimate about REACH by a hub hospital administrator:

Return on investment (of REACH) is very high. A patient that's referred, that actually is a stroke patient that comes into the net as a result of REACH being out there, ends up.... We ended up looking at the first six patients at about a (several thousand dollars) net positive.

By the same token, REACH implied lost revenue for the rural hospitals. A CFO of one rural hospital expressed deep concern over the revenue loss from using REACH at the rural hospitals:

The program is very expensive. The costs of the drugs are very expensive and many times the patients that we're dealing with have no insurance or, in the cases of Medicare or Medicaid, are paid by DRG and that barely covers the cost of the drug itself. So, the economic impact of that is negative to our facility.

According to this CFO, the population base of stroke patients at many rural locations was mainly elderly and insured by Medicare and Medicaid programs. Because those institutions' reimbursement was below the incurred cost, rural hospitals lost money on these patients. The CFO added that the hospital would have reconsidered their adoption of the innovation if this problem had been understood in advance. Similar complaints were echoed by the other rural hospitals. This contradiction did not emerge as significant in the development and early adoption stages because system installation and equipment were financed by the hub hospital with virtually no extra cost for the rural hospitals. However, it became an issue later as the innovation diffused.

\section{Emerging medical practices $v$ s institutionalized insurance practices}

The US healthcare system is currently sustained by public insurance systems, such as Medicare and Medicaid, and private insurers that reimburse providers of medical services. Medical practices and institutionalized insurance practices are mutually dependent and constitute an important identity in the US healthcare system. These opposing elements are inherently in struggle. The emerging medical practices related to REACH were misaligned with insurance regulations for reimbursement. The reimbursement scheme required telemedicine systems to be based on two-way video interaction, a requirement that REACH failed to meet. One of the project initiators commented:

Medicare says we need two-way video for this to be reimbursable and I think that's because that was always the way telemedicine was conceived, you know, that there would be two points... Either we get around that or we build a second in the video, but the other way, from the physician to the ER, and I think either one will take a while.

In addition, the neurologist on the hub side, according to existing regulations, was required to have a medical license in the state in which the patient incident occurred and also be accredited by the rural hospital to participate (via telehealth services) in providing medical service for their patients. As REACH was used more frequently, the struggle of these opposites became more pronounced.

\section{Hub hospital interests vs commercial explorations}

From the technology adoption life cycle and market development life cycle perspective (Moore, 1999, 2004), a successful innovation satisfies the interests of both the owners of the innovation and the stakeholders involved. By the same token, the interests of the hub hospital, the interests of future adopting hospitals, and any commercial exploration of REACH constitute an important identity in attempts to make the telehealth innovation commercially successful. Sponsored by state funds, two entrepreneurs were engaged to commercialize REACH. Rather late in the process of building a business plan for a commercial initiative, negotiations between the hub hospital and the entrepreneurs ended. The hub hospital and the involved entrepreneurs were unable to agree on a business plan that would satisfy the interests of both parties and effectively balance the economic interests between hub and rural hospitals in future adoptions of the innovation. The 
following remark by a hub hospital administrator indicated the deteriorating relationship between the two parties:

So over a series of meetings and telephone calls, the relationships overall began to deteriorate, so it was in a sense (the hub hospital) camp saying we really need some changes in the business plan. The business model just needs some work, and their viewpoint, I assume, was that they didn't need our advice. They knew how to write business plans and, they just said, hurry up and give us this license and let us get to work, and we said - I said, my office is not going to cut a license with any company if it doesn't have what we think is a valid business plan... So our relationship started off nicely and then it took a nose dive.

Without explicating the details of these negotiations, the break-down was an expression of the struggle between the two opposites of this contradiction manifest mainly between the hub hospital and the emerging new organization led by the two entrepreneurs, but also including the complex issue of balancing economic incentives between the hub and rural hospitals in future adoptions of the innovation. The contradiction eventually led to failure of this attempt to radically change the underlying business proposition of the telehealth innovation.

\section{Relationships between contradictions}

In addition to the dynamics related to the struggle between the opposites within each contradiction, there are also important dynamics of interaction between contradictions in a given situation (Israel, 1979; Bjerknes, 1991; Mathiassen, 1998). At any point in time, some contradictions may exercise more influence on the situation than others, and the relative salience of contradictions may change as the situation continues to unfold. We can therefore complement the analysis of individual contradictions by considering relationships between the contradictions involved in adoption of REACH. This analysis further helps us understand the dialectics of resilience as it played out in this particular case of a telehealth adoption.

The contradiction between the medical and the business interests dominated the adoption of REACH from its earliest development. The key stakeholders paid little attention to this contradiction as their promotion of the medical interests shaped the initiative. The contradiction was never resolved and appeared to threaten the long-term success of REACH. This contradiction was also related to the contradiction between economic incentives of the hub hospital and the rural hospitals. While this contradiction remained latent because the hub hospital absorbed most of the costs for equipment and installation, no attempts had so far been made to develop business models that would benefit all involved hospitals. Also, the contradiction between emerging medical practices and institutionalized insurance practices surfaced as a principal contradiction both in the hub and the rural hospitals. This contradiction made hospital management more conscious of the business interests for the telehealth innovation and led them to take a more conservative stance in financing the future of REACH. This in turn made the rural hospitals more attentive to the economic incentives for continued use of the innovation. While the contradiction between the economic incentives of the hub and the rural hospitals did not emerge as a major conflict, the business case for new rural hospitals to become involved remained weak as long as operational deficits continued and as long as the hub hospital expected the rural hospitals to share equipment and installation costs.

In the early adoption stage, the contradiction between the IT-based innovation and the established IT infrastructure emerged as a principal contradiction, as the project team had to deal with a variety of technological challenges in each adopting hospital. The impact of the contradiction was recognized by many stakeholders, but the fundamental contradiction was not resolved in time to avoid similar implementation issues as new rural hospitals became involved. The contradiction between the emerging and the institutionalized work practices and the contradiction between the hub hospital interests and commercialization explorations played minor roles in shaping the trajectory of REACH. However, there had so far not been any successful attempts to implement systematic training and education mechanisms for REACH. Also, it had not so far been possible to involve new configurations of hub and rural hospitals as adopters of REACH, because the contradiction between hub hospital interests and commercial explorations remained unresolved.

\section{Discussion}

We have presented a case study of the adoption of a telehealth innovation. Through the analysis above, we have shown that the initiating project group, the individual hospitals, and the entire network of adopting organizations exhibited considerable resilience in adopting the telehealth innovation. However, our analysis also shows that the telehealth innovation arrived at a critical junction where it could either continue to be used and further diffused as a successful telehealth innovation, or it could be abandoned due to diminished financial support and sagging enthusiasm among key stakeholders. We argue that this crucial point in the innovation process arises because of the inherent contradictions within and across the network of adopting hospitals. The future of the innovation to a large extent depends on how these contradictions develop. From this perspective, resilience is best conceived as an ongoing process in which specific contradictions are confronted and resolved, at least temporarily. Given the interplay among multiple contradictions, each ebbing and flowing over time, resilience is not easily conceived as a general organizational quality. Rather, resilience emerges from one or more organizations' involvement in change processes and their attempts to recognize and resolve the contradictions involved in such efforts.

Our research contributes in this way to understanding organizational resilience as an important process capability in the context of adoption of IT-based innovations. Our study suggests that levels-of-analysis issues should be addressed explicitly in considering organizational resilience. Resilience can be viewed as both a single- and a multilevel construct depending on the research context. We agree with Klein and Myers (1999) that describing the target 
that a researcher aims to explain has become more critical as modern organizations increasingly interact within complex business networks. When researchers deal with network-level phenomena like telehealth innovations, the levels' issue should therefore be carefully considered. As a consequence, our analysis of resilience included both the intra- and inter-organizational levels.

Another important consideration in understanding resilience is the notion of time. We have shown how resilience can be understood in relation to the adoption of IT-based innovations from a process point of view and demonstrated that the resilience of an entity can change over time. In the presented case study, a network of hospitals demonstrated initially high resilience by quickly and successfully adopting a telehealth innovation that in some respects transformed current medical practices. However, the analysis also indicated that the resulting new practices were in some respects fragile and that the adopting hospitals faced emerging contradictions that would influence the future trajectory of the innovation.

In addition, we have demonstrated how the use of dialectics can augment a process perspective. The main assumption behind our analysis is that contradictions are major influences on organizational change. By analyzing the opposing elements of each contradiction, we may understand the paradoxical identity of a phenomenon as well as the dynamic struggle between opposing forces. Moreover, the analysis of the relationships between multiple contradictions allows us to appreciate the shifting requirements of technical innovation (Israel, 1979; Bjerknes, 1991; Mathiassen, 1998). In this case, we identified six contradictions that shaped the adoption of a telehealth innovation, we analyzed the opposites involved in each contradiction, and we considered how the contradictions interacted during the adoption process. The relative importance of opposites and contradictions changed as the adoption process unfolded. In this way, we arrived at an understanding of the dialectics of resilience related to adoption of this particular telehealth innovation.

Finally, the contradictions presented in this study are supported by existing studies on implementation and adoption of healthcare innovations within individual organizations (e.g. Lorenzi et al., 1997; Aarts et al. 1998; Davidson and Chismar, 1999; Berg 2001; Lorenzi and Riley, 2003). Conflicts between emerging and existing work practices are well documented as main reasons of user resistance (Lorenzi et al., 1997; Aarts et al., 1998; Berg, 2001; Kaplan et al., 2001; Lorenzi and Riley, 2003), and other studies have also emphasized insufficient IT infrastructure within the healthcare sector (Anderson, 1997; Fitzmaurice, 1998) and critical issues related to reimbursement and alignment with regulations (Fitzmaurice, 1998; Tanriverdi and Iacono, 1998). However, it is rarely documented how these issues relate and interact in complex processes of adopting healthcare innovations across networks of collaborating hospitals. Our study suggests that healthcare information systems research, especially related to telehealth innovations, need to go beyond organizational boundaries to provide a more comprehensive understanding of these issues in relation to adoption processes. Specifically, the study illustrates how important intra- and inter-organizational issues related to adoption of a telehealth innovation can be understood by employing a dialectical perspective on organizational resilience.

The study has its limitations as well. Most importantly, it draws upon a single case in a US context and it focuses on a particular type of telehealth innovation. Also, there are additional and relevant perspectives on resilience in relation to adoption of IT-based innovations - for example, operational $v s$ strategic level considerations of resilience. Within the limitations of the current study, however, all issues worthy of consideration could not be covered. Future research may pursue additional relevant perspectives on resilience.

\section{Conclusion}

This paper has addressed two questions: (1) How is resilience manifest at the organizational and inter-organizational levels of analysis in the adoption of a telehealth innovation? and (2) How can the use of dialectical analysis augment the analysis of resilience in the adoption of a telehealth innovation? We argue that resilience can be a useful perspective to understand and explain key issues related to adoption of telehealth innovations and IT-based innovations in general. However, organizational resilience needs to be understood more broadly than is currently the case in the literature. Resilience applies across levels of analysis and it changes over time in the particular context of adoption of IT-based innovations. Resilience therefore lends itself well to a dialectical perspective in which the researcher uncovers the contradictions involved and explores how contradictions shape the adoption process. This approach leads to an understanding in which resilience facilitates swift and productive adoption of ITbased innovations while at the same time implicates tensions that endanger further diffusion and the long-term sustainability of the innovation.

\section{References}

Aarts, J. and Peel, V. (1999). Using a Descriptive Model of Change when Implementing Large Scale Clinical Information Systems to Identify Priorities for Further Research, International Journal of Medical Informatics 56: 43-50.

Aarts, J., Peel, V. and Wright, G. (1998). Organizational Issues in Health Informatics: A model approach, International Journal of Medical Informatics 52(3): 235-242.

Anderson, J.G. (1997). Clearing the Way for Physicians' Use of Clinical Information Systems, Communications of the ACM 40(8): 83-90.

Bacharach, S.B., Bamberger, P. and Sonnenstuhl, W.J. (1996). The Organizational Transformation Process: The micropolitics of dissonance reduction and the alignment of logics of action, Administrative Science Quarterly 41(3): 477-506.

Bangert, D. and Doktor, R. (2003). The Role of Organizational Culture in the Management of Clinical e-Health Systems, in 36th Annual Hawaii International Conference System Sciences (Island of Hawaii, USA), 163-171.

Benbasat, I., Goldenstein, D.K. and Mead, M. (1987). The Case Research Strategy in Studies of Information Systems, MIS Quarterly 11(3): 369-386.

Berg, M. (2001). Implementing Information Systems in Health Care Organizations: Myths and challenges, International Journal of Medical Informatics 64(2-3): 143-156.

Bjerknes, G. (1991). Dialectical Reflection in Information Systems Development, Scandinavian Journal of Information Systems 3: 55-77.

Casper, M.L., Barnett, E., Williams, G.I. Jnr., Halverson, J.A., Braham, V.E. and Greenlund, K.J. (2003). Atlas of Stroke Mortality: Racial, Ethnic and Geographic Disparities in the United States. Department of Health and Human Services, Centers for Disease Control and Prevention; January 2003. 
Robey, D. and Boudreau, M.C. (1999). Accounting for the Contradictory Organizational Consequences of Information Technology: Theoretical directions and methodological implications, Information Systems Research 10(2): 167-185.

Robey, D. and Holmstrom, J. (2001). Transforming Municipal Governance in Global Context: A case study of the dialectics of social change, Journal of Global Information Technology Management 4(4): 19-31.

Robey, D., Ross, J.W. and Boudreau, M.C. (2002). Learning to Implement Enterprise Systems: An exploratory study of the dialectics of change, Journal of Management Information Systems 19(1): 17-46.

Robey, D. and Sahay, S. (1996). Transforming Work Through Information Technology: A comparative case study of geographic information systems in county government, Information Systems Research 7(1): 93-110.

Rond, M.D. and Bouchikhi, H. (2004). On the Dialectics of Strategic Alliances, Organization Science 15(1): 56-69.

Sabherwal, R. and Newman, M. (2003). Persistence and Change in System Development: A dialectical view, Journal of Information Technology 18(2): 69-92.

Starr, R., Newfrock, J. and Delurey, M. (2003). Enterprise Resilience: Managing risk in the networked economy, Strategy+Business, Spring 1-10 (htttp:// www.strategy-business.com/).

Tanriverdi, H. and Iacono, C.S. (1998). Knowledge Barriers to Diffusion of Telemedicine, in International Conference on Information Systems (Helsinki, Finland) 39-50.

Van de Ven, A.H. and Poole, M.S. (1995). Explaining Development and Change in Organizations, Academy of Management Review 20(3): 510-540.

Walsham, G. (1995). Interpretive Case Study in IS Research, Nature and Method. European Journal of Information Systems 4: 74-81.

Weick, K.E. (1993). The Collapse of Sensemaking in Organizations: The Mann Gulch disaster, Administrative Science Quarterly 38(4): 628-652.

Yin, R.K. (2003). Case Study Research Design and Methods, 3rd edn., Sage Publications 756-785.

Hamel, G. and Valikangas, L. (2003). The Quest for Resilience, Harvard Business Review 81(9): 52-63.

Hornby, A.S. (1998). Oxford Advanced Learner's Dictionary of Current English, Oxford, UK: Oxford University Press.

Horne III, J.F. (1997). The Coming Age of Organizational Resilience, Business Forum 22(2/3/4): 24-28.

Horne III, J.F. and Orr, J.E. (1998). Assessing Behaviors that Create Resilient Organizations, Employment Relations Today 24(4): 29-39.

Israel, J. (1979). The Language of Dialectics and the Dialectics of Language, Copenhagen: Munksgaard.

Kaplan, B., Brennan, P.F., Dowling, A.F., Friedman, C.P. and Peel, V. (2001) Toward an Informatics Research Agenda: Key people and organizational issues, Journal of the American Medical Informatics Association 8(3): 235-241.

Klein, H.K. and Myers, M.D. (1999). A Set of Principles for Conducting and Evaluating Interpretive Field Studies in Information Systems, MIS Quarterly 23(1): 67-93.

Lorenzi, N.M. and Riley, R.T. (2003). Organizational Issues $=$ Change, International Journal of Medical Informatics 69(2-3): 197-203.

Lorenzi, N.M., Riley, R.T., Blyth, A.J.C., Southon, G. and Dixon, B.J. (1997). Antecedents of the People and Organizational Aspects of Medical Informatics: Review of the literature, Journal of the American Medical Informatics Association 4(2): 79-93.

Maheu, M.M., Whitten, P. and Allen, A. (2001). E-Health, Telehealth and Telemedicine : A Guide to Start-Up and Success, San Francisco: Jossey-Bass.

Mallak, L. (1998). Putting Organizational Resilience to Work, Industrial Management 40(6): 8-13.

Mathiassen, L. (1998). Reflective Systems Development, Scandinavian Journal of Information Systems 10(1\&2): 67-118.

Moore, G.A. (1999). Inside the Tornado: Marketing Strategies from Silicon Valley's Cutting Edge, New York: HarperBusiness.

Moore, G.A. (2004). Darwin and the Demon: Innovating within established enterprises, Harvard Business Review 82(7/8): 86-92.

Raghupathi, W. (1997). Health Care Information Systems, Communications of the ACM 40(8): 80-82.

Reinmoeller, P. and Baardwijk, N.V. (2005). The Link Between Diversity and Resilience, MIT Sloan Management Review 46(4): 61-65.

Riolli, L. and Savicki, V. (2003). Information System Organizational Resilience, Omega: The International Journal of Management Science 31(3): 227-233.

\section{About the authors}

Sunyoung Cho received her master's degree in computer information systems from Georgia State University in 2002 and is currently pursuing a Ph.D. at Georgia State University under the supervision of Dr. Lars Mathiassen. The main research area is information systems in the medical domain, especially telehealth systems. Research interests cover adoption and diffusion factors, and processes of IT-based innovations in the healthcare domain. Her current research is oriented towards a process perspective with views from not only technological and organizational levels but also network and social levels.

Lars Mathiassen received his master's degree in computer science from Aarhus University, Denmark, in 1975, his Ph.D. in informatics from Oslo University, Norway, in 1981, and his Dr. Techn. degree in software engineering from Aalborg University, 1998. He is currently Professor in Department of Computer Information Systems and cofounder of Center for Process Innovation at Georgia State University. His research interests are within information systems and software engineering with a particular emphasis on process innovation. He is a member of IEEE, ACM, and AIS, and coauthor of Computers in Context (Blackwell, 1993), Object Oriented Analysis \& Design (Marko Publishing, 2000), and Improving Software Organizations (Addison-Wesley, 2002). He currently serves as senior editor for MIS Quarterly, and his research is published in journals like Information Systems Research, MIS Quarterly, IEEE Transactions on Engineering Management, Communications of the ACM, Information, Techno$\operatorname{logy}$ \& People, Journal of Strategic Information Systems, Information Systems Journal, Scandinavian Journal of 
Information Systems, Journal of Information Technology, and IEEE Software.

Daniel Robey is a Professor and John B. Zellars Chair of Information Systems at Georgia State University, holding a joint appointment in the Departments of Computer Information Systems and Managerial Sciences. He teaches courses on Qualitative Research Methods, Organization Theory, and Information Technology and Organizational Change. He earned his doctorate in Administrative Science in 1973 from Kent State University. Professor Robey is Editor-in-Chief of Information and Organization and serves on the editorial boards of Organization Science, Academy of Management Review, Information Technology \& People, and the John Wiley series on Information Systems.
Professor Robey is the author of three books and numerous articles in such journals as Management Science, Organization Science, Information Systems Research, MIS Quarterly, Human Relations, Journal of Management Information Systems, ACM Transactions on Information Systems, Information Systems Journal, Academy of Management Review, Academy of Management Journal, Information Technology \& People, and Decision Sciences. His current research includes empirical examinations of the effects of a wide range of technologies on organizational structure and patterns of work. It also includes the development of theoretical approaches in explaining the development and consequences of information technology in organizations. 